\title{
ROLE OF DIFFUSION WEIGHTED MRI IN IMAGING OF PANCREATIC MASSES
}

\author{
Doaa A. Abdelsalam; Laila A. Abdelrahman and Nivan H. Khater
}

Radiologydepartment,
AinShamsUniversity, Cairo,
Egypt
Corresponding Author:
Doaa Abdelaziz Abdelsalam
Email:
doaaaziz18@,yahoo.com.
Mob. +201003955098
Received: 20/8/2020
Accepted: 7/9/2020

Online ISSN: 2735-3540

\begin{abstract}
Back ground: Pancreatic cancer is the fourth most common cause of cancer-related mortality worldwide, and the five-year survival rate is less than 5\%. Therefore, it seems to remain one of the greatest challenges in the fight against cancer in the $21^{\text {st }}$ century. Magnetic resonance imaging (MRI) has a well-established role in the evaluation of patients with pancreatic masses. The implementation of ultrafast imaging techniques made DWI of the upper abdomen a feasible option and many studies indicate that DWI is promising in pancreatic imaging.
\end{abstract}

Aim of the work: To evaluate the role of diffusion weighed MRI in the assessment of different pancreatic masses.

Patients \&Methods: This study included twenty two cases presented with pathological and or radiological evident pancreatic lesions.

Results: Of the 22 subjects, 9 out of 10 malignant lesions were correctly classified as malignant (TP) \&11 out of the 12 benign lesions were correctly classified as benign (TN). A sensitivity of $90 \%$ was achieved, with a specificity of $91.7 \%$. The Positive predictive value was $90 \%$, while the negative predictive value was $91.7 \%$.

Conclusion: Diffusion weighted MRI is a useful tool in evaluating different pancreatic lesions and provides helpful information for the detection and characterization of a wide variety of pancreatic neoplasms, including both solid and cystic lesions.

Keywords: Pancreas; ADC; Pancreatic neoplasms; Diffusion weighted MRI;

\section{INTRODUCTION:}

Pancreatic neoplasms can be detected and characterized at conventional and functional MR imaging ${ }^{(1,2)}$. Conventional MR imaging has become more widely used in the diagnosis of pancreatic neoplasms because of its exceptional soft-tissue contrast resolution $^{(3,4)}$.

Regarding the DWI, it is mainly based on Brownian motion (random thermal diffusion) which discusses the movement of small molecules within a tissue. On applying diffusion weighting to a sequence which is the combination of pulses and strong gradients, we can calculate the ADC value in a given tissue and thus quantify the gathered effects of capillary perfusion and diffusion of water molecules ${ }^{(5)}$.

Using DWI as a helpful tool in diagnosing neoplastic diseases depends on basis that malignant cells have larger volume and more close alignment. That hypercellularity reduces extracellular space causing restriction of free movement of water particles thus reducing the ADC value and giving hyperintense signal on DWI ${ }^{(5)}$. 
On the contrary, benign lesions are hypocellular and cause expansion of the extracellular space, which in turn causes free diffusion of the water molecules thus increasing the ADC value with hypointense signal on $\mathrm{DWI}^{(5)}$.

\section{PATIENTS AND METHODS:}

\section{Study population:}

\section{Inclusion criteria}

1. Patients with a pancreatic lesion, which is histopathologically proven either post-surgical or following a true cut or fine needle biopsy/ aspiration $(\mathrm{n}=15)$.

2. Cases who were diagnosed comfortably upon clinical evaluation, laboratory studies and or follow-up radiological examinations $(n=7)$.

\section{Exclusion criteria:}

1. Patients which were claustrophobic to MRI examination.

2. Diffusion-weighted sequences which were significantly degraded by motion.

\section{Patient preparation:}

Patients fast for 4 hours before the MRI examination in order to optimize visualization of the pancreatico-biliary tree.

\section{MRI technique:}

MR imaging was performed on high field system (1.5 Tesla) magnet units General Electric (GE) and Philips Achiva sets.

Initial imaging consisted of axial T2weighted fast spin-echo imaging (T2-WI) with fat suppression, in cases with contrast study $(\mathrm{n}=18)$; T1-weighted dynamic contrastenhanced imaging (T1-WI) with fat suppression, DWI was acquired through the pancreas at 20 slice locations utilizing a finger pulse-triggered diffusion-weighted single-shot spin-echo. All axial images were reconstructed to $256 \times 256$ matrix images after scanning.

\section{Imaging evaluation:}

The morphological features of each lesion recorded included size, shape, margin, signal characteristics, pattern of enhancement in cases with contrast study as well as site of the lesions. Then provisional diagnosis was reported. Second, we reviewed the diffusion images with ADC values for final radiological characterization and detection of the pancreatic lesions.

\section{ADC calculation:}

1. The mean ADC: ADC of each lesion detected was measured by drawing a region of interest over the lesion within the boundaries of the lesion. It was manually placed such that it is smaller in size than the actual lesion and did not include adjacent normal tissue.

2. ADC of the eligible normal pancreatic parenchymal tissue.

3. Normalized ADC value using the pancreatic parenchyma as a reference organ in the characterization of focal pancreatic lesions.

\section{Statistical analysis:}

Statistical analysis was performed using Med Calc statistical software for Windows (Med Calc Software, Mariakerke, Belgium).

Data for continuous variables were expressed as either median, inter quartile range and range or mean \pm standard deviation and as both number and percentage for categorical data.

Mann-Whitney U-test was used to evaluate the differences in mean and normalized ADC values between benign and malignant groups.

Comparisons of mean and normalized ADC between the cystic pancreatic lesion groups were performed using ANOVA test. 


\section{Role of Diffusion Weighted MRI in Imaging of Pancreatic Masses}

The diagnostic accuracy of all variables was evaluated in terms of sensitivity, specificity, positive predictive value (PPV), negative predictive value (NPV), and area under the ROC curve (AUC).

For all tests all $\mathrm{P}$ values were two-tailed and a P-value $<0.05$ was considered significant.

\section{Interpretation of results:}

22 patients (11 males and 11 females) were included in this study.

Histopathological analysis and or clinical/radiological evidence revealed that $12(54.5 \%)$ and $10(45.5 \%)$ of the pancreatic lesions in this study were benign and malignant respectively (Table 1).

\begin{tabular}{|c|c|c|}
\hline Final pathologic diagnosis & No. of cases & Percentage \\
\hline Benign & 12 & $54.5 \%$ \\
\hline Malignant & 10 & $45.5 \%$ \\
\hline Total & 22 & $100 \%$ \\
\hline
\end{tabular}

The benign lesions comprised 2 intraductal papillary mucinous neoplasm (IPMN), 2 mucinous cystadenomas, 1 solid pseudo-papillary tumor (SPT), 1 splenule, 1 mass-forming necrotizing pancreatitis, 1 serous cystadenoma (SCA), 3 pancreatic pseudocysts (PC) and 1 insulinoma (Diag.1). The malignant lesions comprised 9 Adenocarcinomas (AC) and 1 mucinous cystadenocarcinoma (Diag.2).

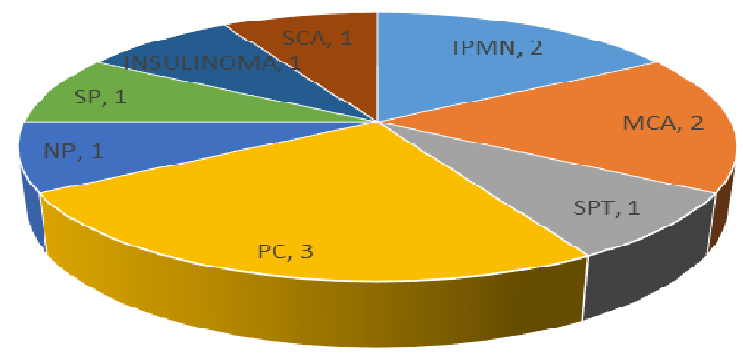

Diagram1: Pie chart showing the contribution of the various types of benign pancreatic lesions.

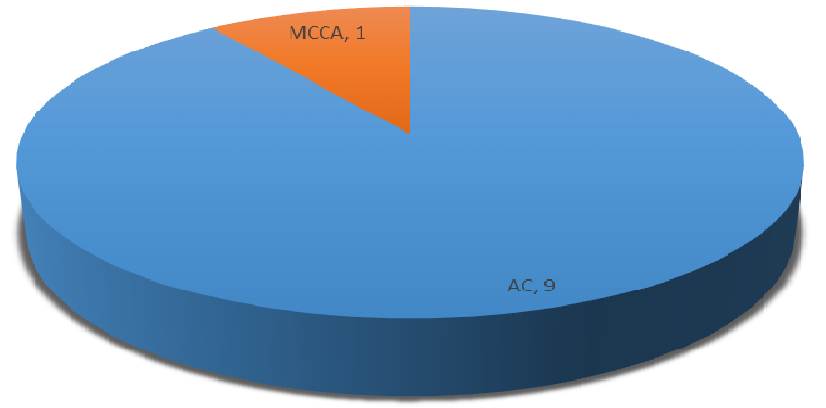

Diagram2: Pie chart showing the contribution of the different types of malignant pancreatic lesions.

AC - adenocarcinoma, MCCA - mucinous cystadenocarcinoma.

When the pancreatic lesions were categorized as benign or malignant, both groups could be differentiated using mean and normalized (comparing to the normal pancreatic tissue) ADC values. Benign tumors showed statistically significantly higher mean $\mathrm{ADC}$ values $(\mathrm{P}=0.0005)$ and normalized ADC values $(\mathrm{P}=0.0003)$, however overlap was seen among the individual mean ADC values and to a lesser extent among the normalized ADC values of both groups (Table 2). 


\section{Doaa A. Abdelsalam, et al.}

Table 2:Mean and normalized ADC values for benign and malignant groups. Data are expressed in median, interquartile range and range.

\begin{tabular}{|l|c|c|c|}
\hline & Benign tumors & malignant tumors & P value \\
\hline Mean ADC & & & \\
Median & 2.54 & 1.14 & \\
IQR & $1.73-2.86$ & $0.95-1.28$ & $\mathrm{P}=0.0005$ \\
Range & $1.13-4.04$ & $0.9-1.67$ & \\
\hline Normalized ADC & & & \\
Median & 1.83 & 0.73 & \\
IQR & $1.34-2.03$ & $0.67-0.79$ & $\mathrm{P}=0.0003$ \\
Range & $0.77-2.24$ & $0.63-1.04$ & \\
\hline
\end{tabular}

Using a mean ADC threshold value of $\leq 1.34,9$ out of 10 malignant lesions were correctly classified as malignant (TP) while only one lesion (adenocarcinoma with a cystic component) had an ADC of more than 1.34 (1.67) and was incorrectly classified as benign (FN). Eleven out of the twelve benign lesions had ADC values that were more than 1.34 and were correctly classified as benign (TN). A single benign lesion (splenule) had an ADC value of less than 1.34 (1.13) and was inaccurately classified as malignant (FP).
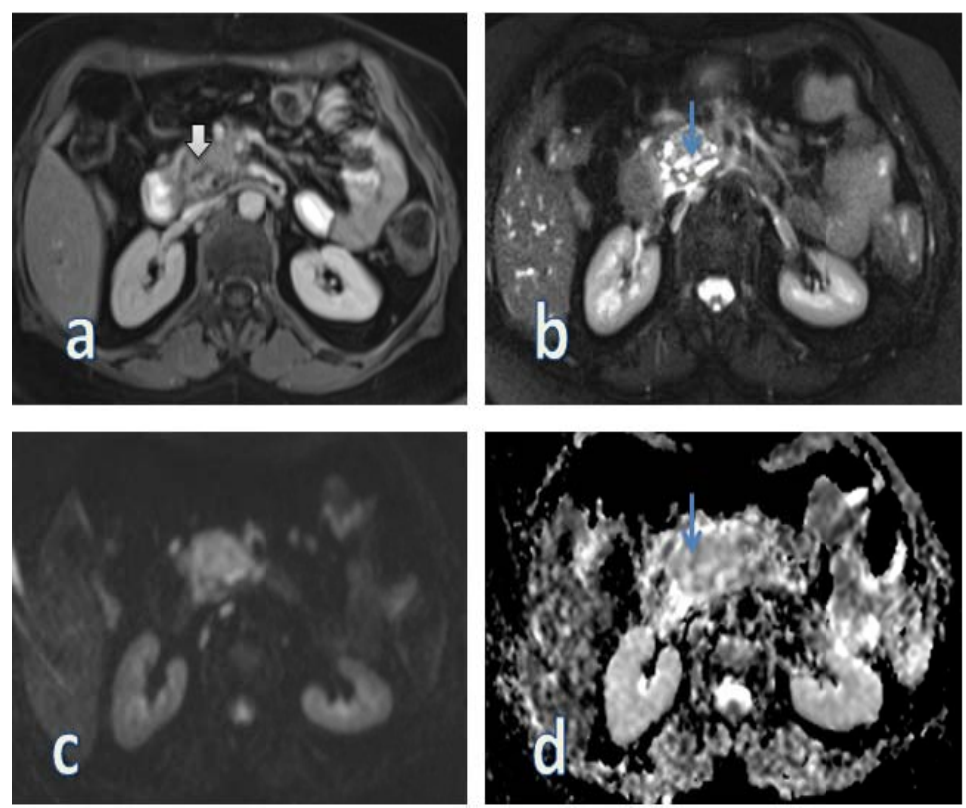

1:A 52-year-old female patient with histopathologically proved pancreatic adenocarcinoma. The lesion showed heterogeneous enhancement in post contrast T1WI (white arrow) (a) and heterogeneous hyper intense cystic areas (blue arrow) of degeneration at T2WI (b). It displayed high signal intensity in DW images (c) compared with the adjacent parenchyma and low signal intensity areas (blue arrow)on corresponding ADC map, the ADC value at the tumor area measures $1.670 \mathrm{x} 10-3 \mathrm{~mm} 2 / \mathrm{sec}$ 

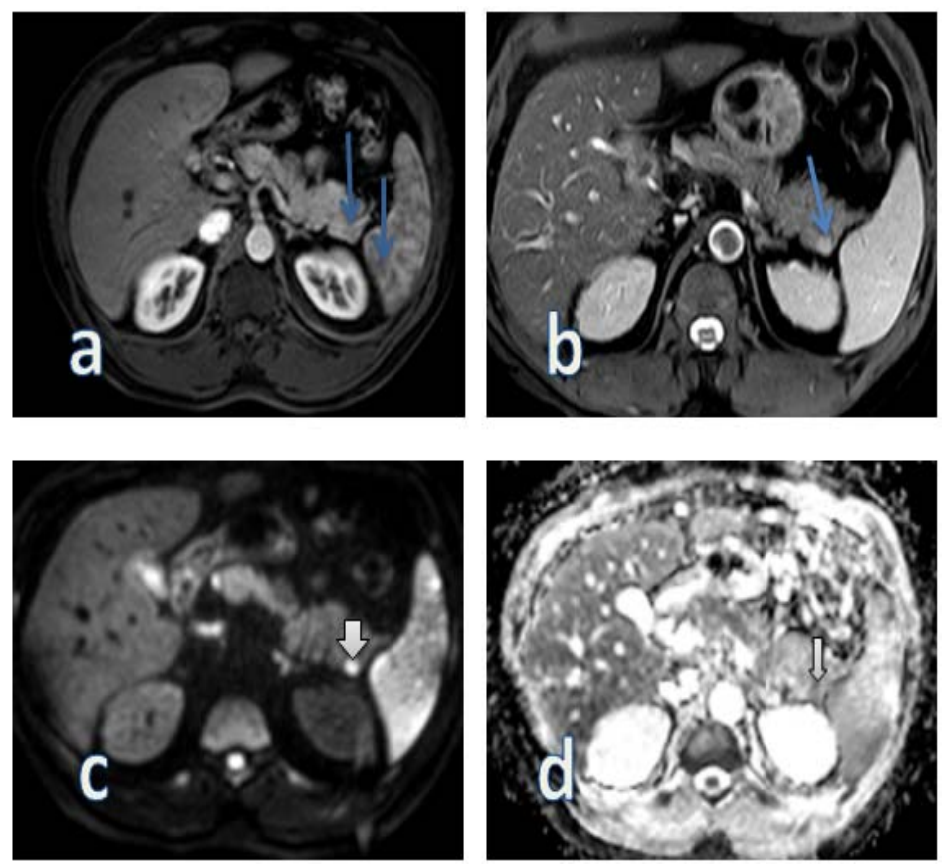

Fig. 2: A 50-year-old male patient with pancreatic tail sharply demarcated stable nodule that follow the splenic signal in all pulse sequences proved to be pancreatic tail splenule. The lesion showed enhancement similar to the adjacent spleen in post contrast T1WI (blue arrows) (a) and hyper intense signal(blue arrow) to the pancreas at T2WI (b). It displays high signal intensity(white arrow) in DW images (c) compared with the adjacent parenchyma and low signal intensity(narrow white arrow) on corresponding ADC map, the ADC value at the lesion measured $1.27 \times 10-3 \mathrm{~mm} 2 / \mathrm{sec}$, almost the same value of the adjacent spleen which is $1.28 \times 10-3 \mathrm{~mm} 2 / \mathrm{sec}(\mathrm{d})$.
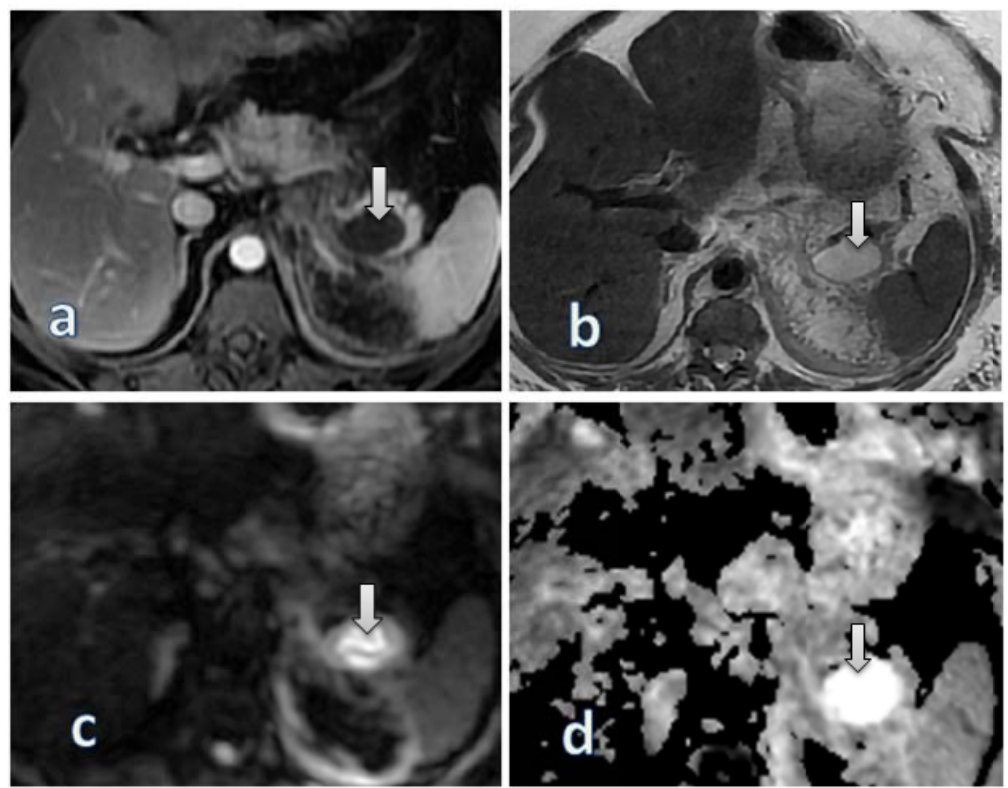

Fig. 3: A 56-year-old female patient with pancreatic pseudocyst. The lesion showed low signal intensity with no enhancement in T1WI contrast study (white arrow) (a) and hyper intense signals to the pancreas at T2WI (b). It displayed high signal intensity in diffusion weighted image (c) and high signal intensity on corresponding ADC map (T2 sine through effect) and the ADC value of the cystic lesion measured $4.035 \times 10-3 \mathrm{~mm} 2 / \mathrm{sec}$ (d). 


\section{DISCUSSION:}

Although contrast enhanced MRI is considered the routine protocol it is time consuming, requires adequate patient cooperation in breath hold technique in addition to cost, adverse effects and contraindications of contrast media. Hence the great need for another imaging modality gives the same information but avoids the drawbacks of contrast enhanced technique.

DWI is based on Brownian motion, used to assess the diffusion process of molecules in vivo. The water molecules diffuse within the extracellular as well as the intracellular components of tissues by different speeds and because of the presence of cellular membranes in the intracellular component; the diffusion of water molecules is slow. The more the cellular membranes, the slower the diffusion becomes ${ }^{(6)}$.

Thus, ADCs, which are defined as the quantitative measurement of the diffusion characteristics of tissues, are therefore in relation to the extra-cellular as well as intracellular components. ADC values are reduced with tissue hyper-cellularity ${ }^{(6)}$.

It hasd been proved that the cell density is proportional to tumoral aggressiveness; several studies suggested a relation between tumors hyper-cellularity and increased metastatic capacity ${ }^{(6)}$.

Our current study aimed to determine the usefulness of DWI in characterizing pancreatic pathology whether it is benign or malignant using ADC measurement.

The current study was conducted including twenty two patients, 10 malignant, 4 inflammatory and 8 benign.

In our study sensitivity of DW MRI was 91\%, specificity $91.7 \%$, NPV $91.7 \%$ and PPV 90\%.

These results are showing no major difference with results of Nikolaos et al. ${ }^{(7)}$ in which DWI had 92\% sensitivity and 97\% specificity with a PPV $85 \%$ and NPV $98 \%$

In the current study, ADC value of malignant pancreatic neoplasms was signifycantly reduced than that of the normal pancreas with mean values of $1.34 \times 10^{-3} \mathrm{~mm}^{2} / \mathrm{s}$ and $1.519 \times 10^{-3} \mathrm{~mm}^{2} / \mathrm{s}$ respectively in-keeping with the results of Wen et al. ${ }^{(8)}$, Matsuki et al. ${ }^{(9)}$ and Nikolaos et al. ${ }^{(7)}$ which all reported that mean ADC values of malignant neoplasms of the pancreas were significantly reduced than those of normal pancreas.

\section{Their results were as follows:}

- Nikolaos et al. ${ }^{(7)}$ : mean ADC values for malignant pancreatic tumors were $1.40 \times 10^{-3} \mathrm{~mm}^{2} / \mathrm{s}$ while normal pancreas mean ADC values were 1.61 $\times 10^{-3} \mathrm{~mm}^{2} / \mathrm{s}$.

- Wen et al. ${ }^{(8)}$ : mean ADC values for pancreatic carcinoma were $1.06 \times 10^{-3} \mathrm{~mm}^{2} / \mathrm{s}$ while normal pancreas mean ADC values were $1.47 \times 10^{-3} \mathrm{~mm}^{2} / \mathrm{s}$.

- Matsuki et al. ${ }^{(9)}$ : mean ADC values for pancreatic carcinoma were 1.43 $\times 10^{-3} \mathrm{~mm}^{2} / \mathrm{s}$ while normal pancreas mean $\mathrm{ADC}$ values were $1.90 \times 10^{-3} \mathrm{~mm}^{2} / \mathrm{s}$.

There was one false positive lesion in DWI in our study, a small pancreatic tail splenule that showed relative low ADC value of $1.27 \times 10-3 \mathrm{~mm} 2 / \mathrm{sec}$. Kang et al. ${ }^{(10)}$ mentioned that splenic tissue shows dense cellularity and is relatively restricted to other abdominal organs in DWI study.

Our study showed only one false negative lesion, an adenocarcinoma in a patient with past history of receiving chemotherapy. The false negative result may represent a good response to treatment. However, larger studies are needed to assess whether DWI can be used to evaluate the response after chemotherapy. It also may be related to low or moderate grade of the 
tumor with loose fibrosis according to the results of the study by Wen et al. ${ }^{(8)}$ and these kinds of tumors show relatively high ADC values. Alsothe lesion showed tumor necrosis, necrosisgave low signal in DWI (facilitated diffusion) and high ADC values in contrary to the viable tumor tissue which showed restricted diffusion pattern (bright signal in DWI and low ADC values). The ability of DWI to detect tumor necrosis can be used prior to biopsy to avoid the site of necrosis and thus avoids insufficient and false negative biopsies.

Our study showed a number of limitations which included the small study population, so larger sample size is needed to confirm our results, secondly the study included very limited non-malignant cases. Lastly was the unopposed artifacts mostly related to the respiratory motion in some cases which may cause to some degree errors of the ADC value measurement.

\section{Conclusion:}

Combined qualitative and quantitative analysis of DWIs and ADC values respectively made the results of DW MRI approach reliable for better evaluation of different cystic and solid pancreatic lesions. Using DWI in conjunction with conventional imaging as a useful modality aids in assessment of pancreatic neoplasms. In cases with contraindication to contrast administration, DWI can be used as an acceptable alternative technique to contrastenhanced imaging.

\section{REFERENCES:}

1. Eun S.L and Jeong M.L: Pancreaticcancer. World J Gastroenterol, 2014; 20(24):78647877.

2. Riccardo De Robertis, Paolo Tinazzi Martini, Emanuele Demozzi, Flavia Dal Corso, Claudio Bassi, Paolo Pederzoli, and
Mirko D'Onofrio: Diffusion-weighted imaging of pancreatic cancer. World $\mathrm{J}$ Radiol, 2015; 7 (10): 319-328.

3. MatsukiM, Inada $Y$, Nakai G, Tatsugami F, Tanikake M, NarabayashiI, Masuda D, Arisaka Y, Takaori K, Tanigawa N: Diffusion-weighted MR imaging of pancreatic carcinoma. Abdom Imaging, 2007; 32 (4):481-483.

4. $\mathrm{Ku} \mathrm{YM}$, Shin SS, Lee $\mathrm{CH}$, Semelka RC. Magnetic resonance imaging of cystic and endocrine pancreatic neoplasms. Top Magn Reson Imaging 2009; 20(1):11-18.

5. R.L. Robertson, CM. Glasier Diffusionweighted imaging of the brain in infants and children. Pediatr Radiol, 37 (8) (2007), pp. 749-768CrossRefView Record in Scopus Google Scholar

6. Helmberger TK. Parenchymal disease of pancreas in clinical MRI of the abdomen gortsoyiannis. In: NC, editor. "Why, How, When"; 2011. p. 225-55.

7. Nikolaos K., Terri L., Peter A., Johan P., Nils A. Diffusion-weight edmagnetic resonance imaging of pancreas tumours Eur Radiol, 19 (2009), pp. 1981-1990

8. Wen $\mathrm{CH}$, Jing $\mathrm{S}$, Shi YC, Jian PL. Differentiation between pancreatic carcinoma and mass-forming chronic pancreatitis: usefulness of high $b$ value diffusion-weighted imaging. J Digest Dis, 12 (2011), pp. 401-408

9. Ichikawa T., Erturk S.M., Motosugi U., Sou H., Iino H., Araki T., etal.High-b value diffusion-weighted MRI for detecting pancreatic adenocarcinoma: preliminary results AJR Am J Roentgenol, 188 (2) (2007), pp. 409-414

10. Bo-Kyeong Kang, JinHee Kim, Jae Ho Byun, Seung Soo Lee, et al. Diffusionweighted MRI: usefulness for differentiating intrapancreatic accessory spleen and small hypervascular neuro-endocrine tumor of the pancreas: Acta Radiol published online 20 November 2013 DOI: $10.1177 / 0284185113513760$ 


\section{Doaa A. Abdelsalam, et al.}

\section{دور الرنين المغتاطيسي بخاصية الانتشار الجزيئي في تقييم تكتلات البنكرياس}

\section{ملخص البحث}

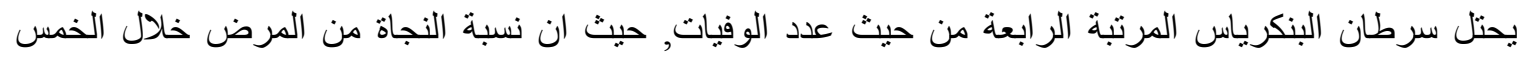
سنوات الاولي من الاصابة لا تتعدي ٪\% ولذية الزلك يبقي سرطان البنكرياس من التحديات المرضية الصعبة خلال القرن

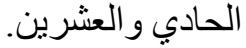

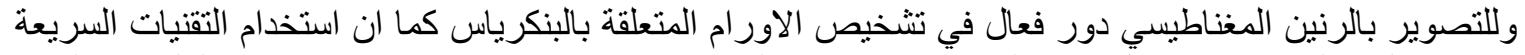

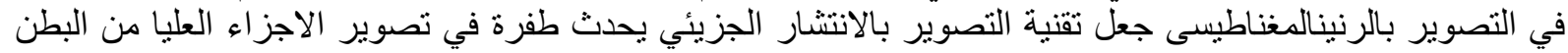

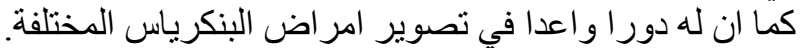

\section{الهزف منالبحث}

الهذف من الدراسة الحالية هو تقييم فعالية وحساسية التصوير بالرنين المغناطيسي بخاصية الانتشار الجزيئي في تشخيص تكتلات البنكرياس.

\section{الموضوع وطرق البحث}

اشتملت هذه الدراسة علي Y مريضيعانى من وجود اعتلال وتكتلات بالبنكرياس في قسم الأشعة التشخيصبة في التئي

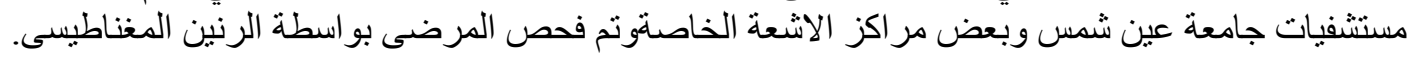

النتائج

من بين اثنتين و عشرين مريض وجد عشر حالات يعانون من اورام خبيثة بالبنكرياس و اثنتي عشر حالة لديهر

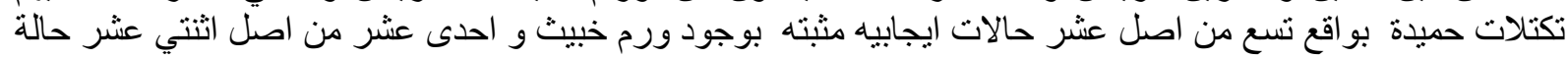

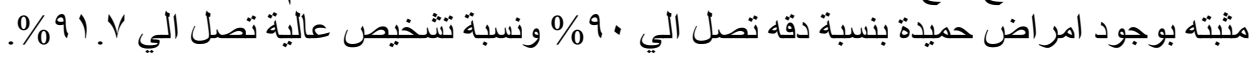

\section{الخلاصة}

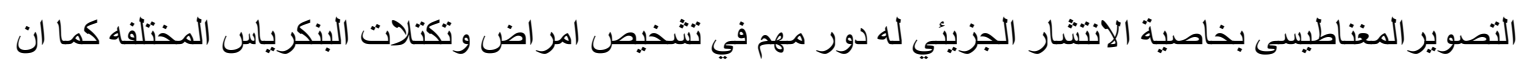
له دورا فعالا في توصيف العديد من التكتلات سواء الصلبه التئه او الكيسية. 